\title{
Effect of Process Parameters on Fatigue and Fracture Behavior of Al-Cu-Mg Alloy after Creep Aging
}

\author{
Lihua Zhan ${ }^{1,2, *}$, Xintong $\mathrm{Wu}^{1,2}$, Xun Wang ${ }^{1,2}$, Youliang Yang ${ }^{1,2}$, Guiming Liu ${ }^{1,2}$ \\ and Yongqian $\mathrm{Xu}{ }^{1,3}$ \\ 1 State Key Laboratory of High-Performance Complex Manufacturing, Central South University, \\ Changsha 410083, China; wuxintong@csu.edu.cn (X.W.); doudouaitutu1112@163.com (X.W.); \\ 133711090@csu.edu.cn (Y.Y.); 163712126@csu.edu.cn (G.L.); yongqian.xu@csu.edu.cn (Y.X.) \\ 2 School of Mechanical and Electrical Engineering, Central South University, Changsha 410083, China \\ 3 Light Alloy Research Institute, Central South University, Changsha 410083, China \\ * Correspondence: yjs-cast@csu.edu.cn
}

Received: 2 April 2018; Accepted: 21 April 2018; Published: 26 April 2018

\begin{abstract}
A set of creep aging tests at different aging temperatures and stress levels were carried out for Al-Cu-Mg alloy, and the effects of creep aging on strength and fatigue fracture behavior were studied through tensile tests and fatigue crack propagation tests. The microstructures were further analyzed by using scanning electron microscopy (SEM) and transmission electron microscopy (TEM). The results show that temperature and stress can obviously affect the creep behavior, mechanical properties, and fatigue life of $\mathrm{Al}-\mathrm{Cu}-\mathrm{Mg}$ alloy. As the aging temperature increases, the fatigue life of alloy first increases, and then decreases. The microstructure also displays a transition from the Guinier-Preston-Bagaryatsky (GPB) zones to the precipitation of $S$ phase in the grain interior. However, the precipitation phases grow up and become coarse at excessive temperatures. Increasing stress can narrow the precipitation-free zone (PFZ) at the grain boundary and improve the fatigue life, but overhigh stress can produce the opposite result. In summary, the fatigue life of $\mathrm{Al}-\mathrm{Cu}-\mathrm{Mg}$ alloy can be improved by fine-dispersive precipitation phases and a narrow PFZ in a suitable creep aging process.
\end{abstract}

Keywords: $\mathrm{Al}-\mathrm{Cu}-\mathrm{Mg}$ alloy; creep aging; fatigue fracture behavior; microstructure

\section{Introduction}

Creep aging forming is a kind of forming method using the combination of the creep deformation of metal and the aging of aluminum alloy, which is mainly used for manufacturing aircraft wing panels and other integral panel components. This method is of better forming precision and repeatability than that of conventional plastic forming, which reduces the possibility of material fracture in the process and the residual stress in the components [1-5]. In recent years, the research on the formation of creep aging has mainly focused on how to improve microstructures, mechanical properties, or forming precision. Ho et al. [6] presented a creep damage constitutive equation for creep aging through forming a springback simulation that considered precipitation phases change in view of the 7010 aluminum alloy. Zhan [7] improved on that model, and built a set of constitutive models that can simulate the change of creep strain, precipitation phase, dislocation strengthening, solid solution strengthening, aging reinforcement, and material properties of the forming process in combination with the creep unidirectional tensile test. Xu et al. [8] compared the precipitation behaviors of 2124 aluminum alloy under several aging forming conditions, finding that the key mechanism of the generation and control of the precipitation orientation effect of 2124 aluminum alloy lies in the effect of dislocation. Based on creep aging experimental data, Yang et al. [9] presented a constitutive modeling and springback 
simulation for 2524 aluminum alloy that was much closer to experimental results. These research studies have been gradually applied to manufacturing, which makes it possible to transform high performance aluminum alloy into complex components by creep aging forming. However, with the development of the aerospace industry, the components are faced with more complex and extreme service conditions, which require that the materials have not only good strength and toughness, but also excellent comprehensive performance.

The importance of these problems was recognized, and more studies on the service performance of aluminum alloy were carried out. Chen et al. [10] reported on the effects of inclusions, grain boundaries, and grain orientations on the fatigue crack initiation and propagation behaviors of 2524 aluminum alloy, finding that coarse inclusion particles drastically accelerate local crack growth rates and that fatigue crack shows a strong tendency to propagate transgranularly grains with high Schmid factors. Siddiqui [11], Liu [12], and Chen et al. [13] studied the effects of different aging treatments on the fatigue behavior of aluminum alloy in various environments. They focused on the relationship between microstructures and fatigue behavior, and proved that fatigue crack propagation was influenced by the aging time and temperature, which indicated that the fatigue with aging time resistance was linked to the vacancies that were assisted by the diffusion mechanism and dislocation movement. Although the effect of aging temperature on the comprehensive performance of aluminum alloy has been demonstrated in the last decades, little attention has been paid to the fatigue behavior of aluminum alloy after creep aging. At present, studies about creep aging mainly concentrate on finding out the creep aging strengthening behavior (mechanical property) of materials under different process parameters, regarding the peak strength of material as the basis of determining the best technological system of creep aging. Zhou [14] and Chen [15] studied the effects of aging and creep aging on the mechanical properties, fatigue crack growth performance, and exfoliation corrosion of aluminum alloy.

In this work, a widely used Al-Cu-Mg alloy for aerospace was used as the research object [16-19], and the microstructures were analyzed by scanning electron microscopy (SEM), and transmission electron microscopy (TEM). The purpose of this paper is to analyze the effects of different creep aging parameters on creep behavior, mechanical property, and fatigue fracture behavior of aluminum alloy. This work could provide basic technological parameters and theory for the manufacturing of large components so as to improve the development of creep aging.

\section{Experimental}

\subsection{Samples and Heat Treatment}

The experimental materials used were supplied in the form of homogenized rolled sheets, whose chemical composition is listed in Table 1. The initial state is T3, which refers to cold processing after solution treatment followed by natural aging and then a basically stable state. The samples were taken along the longitudinal (L) direction, which refers to GB/T2039-2012 (metallic materials-uniaxial creep testing method in tension), as shown in Figure 1. Figure 2 shows the stress-strain curve of the initial sample. The Young modulus, tensile strength, yield strength, and elongation of the initial sample are as follows: $69.2 \pm 0.8 \mathrm{GPa}, 460.3 \pm 3.4 \mathrm{MPa}, 307.4 \pm 4.8 \mathrm{MPa}, 21.6 \pm 0.6 \%$ (Five horizontal samples were taken). Conventional artificial aging treatment and creep aging treatment were conducted on a plate, for which a RMT-D10 electron creep slackness tester (Zhuhai SUST Electrical Equipment Co., Ltd., Zhuhai, China) was adopted for creep aging. The temperature of creep aging was selected at $433 \mathrm{~K}, 453 \mathrm{~K}$, and $473 \mathrm{~K}$ respectively. The creep stress was selected as $0 \mathrm{MPa}, 180 \mathrm{MPa}$, and $210 \mathrm{MPa}$, respectively, and the aging time was $12 \mathrm{~h}$.

Table 1. Main chemical composition of $\mathrm{Al}-\mathrm{Cu}-\mathrm{Mg}$ alloy (mass fraction, \%).

\begin{tabular}{ccccccccc}
\hline $\mathbf{C u}$ & $\mathbf{M g}$ & $\mathbf{M n}$ & $\mathbf{F e}$ & $\mathbf{Z n}$ & $\mathbf{T i}$ & $\mathbf{C r}$ & $\mathbf{S i}$ & $\mathbf{A l}$ \\
\hline 4.26 & 1.36 & 0.57 & 0.037 & 0.024 & 0.01 & 0.002 & 0.089 & Bal. \\
\hline
\end{tabular}




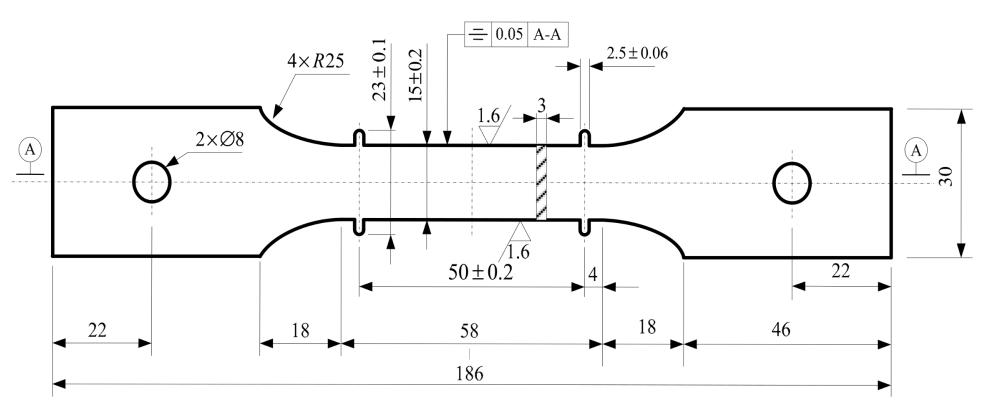

Figure 1. Standard creep aging sample (unit: $\mathrm{mm}$ ).

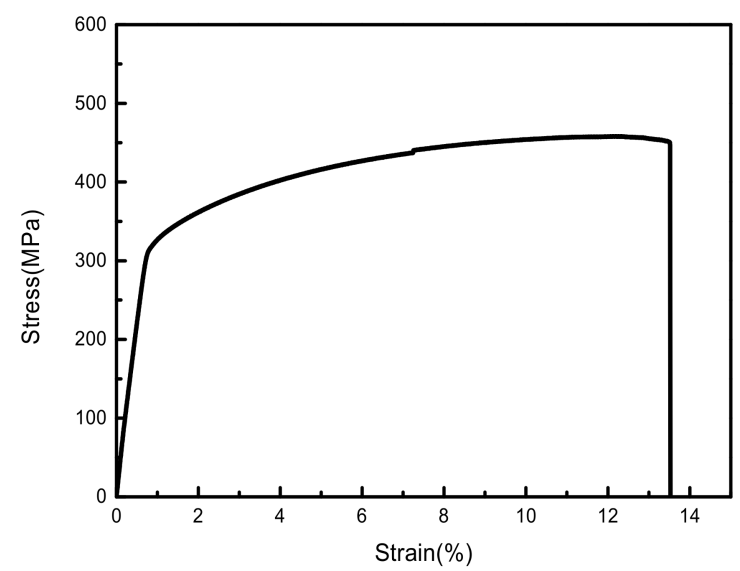

Figure 2. Stress-strain curve of the initial sample.

\subsection{Tensile and Fatigue Testing}

Tensile testing was carried out for the materials of different creep process parameters at room temperature on the E45 type testing machine (MTS Systems Corporation, Eden Prairie, MN, USA) with $2 \mathrm{~mm} / \mathrm{min}$ loading speed. All of the fatigue tests were conducted through sine-wave loading at a stress ratio $\left(\mathrm{R}=\sigma_{\min } / \sigma_{\max }\right)$ of $0.1(30 / 300 \mathrm{MPa})$ with a loading frequency of $10 \mathrm{~Hz}$ on an MTS810 tester machine (MTS Systems Corporation, Eden Prairie, MN, USA) fatigue tester at room temperature in a laboratory air environment. For each state, five horizontal samples were taken.

\subsection{Microstructural Analysis}

Fatigue fracture surfaces of the samples that were cyclically deformed in fatigue testing were analyzed by a TESCAN scanning electron microscope (Tescan company, Brno, Czech) so as to study the production and expansion of cracks. Samples suitable for a transmission electron microscope (TEM) were thin $0.8 \mathrm{~mm}$ slices that were electropolished by using twin-jet equipment with a voltage of $15 \mathrm{~V}$ in a $30 \%$ nitric and $70 \%$ methanol mixture acid at approximately $-30{ }^{\circ} \mathrm{C}$, after which the slices were cleaned in ethanol at room temperature for at least $5 \mathrm{~min}$. These were then examined on a Tecnai $\mathrm{G}^{2}$ 20 TEM (United States FEI limited liability company, Hillsboro, OR, USA) machine operated at 200 kV.

\section{Results and Discussion}

\subsection{Creep Behavior of Alloy}

As shown in Figure 3, the curves of Al-Cu-Mg alloy were measured under different aging temperature and stress levels after $12 \mathrm{~h}$ of aging. The creep and steady-state creep rate at different aging temperature and stress levels are listed in detail in Table 2. From Figure 3 and Table 2, at the same temperature, the creep strain and steady-state creep rate rise with the increase of stress. At $180{ }^{\circ} \mathrm{C}$, 
the creep strain is $0.145 \%$ under a stress level of $180 \mathrm{MPa}$ after $12 \mathrm{~h}$ of aging, while the creep increases to $0.169 \%$ under a stress level of $210 \mathrm{MPa}$. Moreover, the steady-state creep was also improved from $7.58 \times 10^{-3}$ to $8.42 \times 10^{-3}$ with the changed stress. At the same stress, the creep strain and steady-state creep rate also grow with the rise in temperature. When the stress level is $180 \mathrm{MPa}$, the creep strain is $0.068 \%$ after $12 \mathrm{~h}$ of aging at $160{ }^{\circ} \mathrm{C}$. When the temperature increases to $200{ }^{\circ} \mathrm{C}$, the creep strain is $0.235 \%$, which is 3.5 times that at $160^{\circ} \mathrm{C}$. Meanwhile, the steady-state creep rate $\left(1.033 \times 10^{-2}\right)$ at $200{ }^{\circ} \mathrm{C}$ is 3.1 times that at $160{ }^{\circ} \mathrm{C}\left(3.3 \times 10^{-3}\right)$.
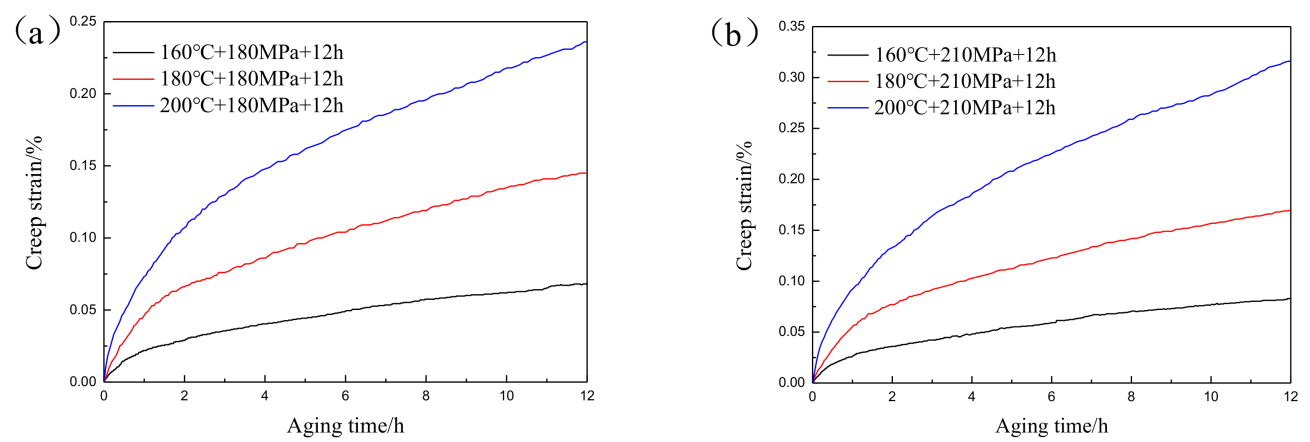

Figure 3. Creep curves of Al-Cu-Mg alloy under different aging temperature and stress levels: (a) $180 \mathrm{MPa}$; (b) $210 \mathrm{MPa}$.

Table 2. Creep strain and steady-state creep rate of Al-Cu-Mg alloy under different aging temperature and stress levels.

\begin{tabular}{cccc}
\hline Temperature $/{ }^{\circ} \mathbf{C}$ & Stress/MPa & Creep Strain $/ \%$ & Steady-State Creep/s \\
\hline \multirow{2}{*}{160} & 180 & 0.068 & $3.3 \times 10^{-3}$ \\
& 210 & 0.082 & $4.02 \times 10^{-3}$ \\
\hline \multirow{2}{*}{180} & 180 & 0.145 & $7.58 \times 10^{-3}$ \\
& 210 & 0.169 & $8.42 \times 10^{-3}$ \\
\hline \multirow{2}{*}{200} & 180 & 0.235 & $1.033 \times 10^{-2}$ \\
& 210 & 0.315 & $1.46 \times 10^{-2}$ \\
\hline
\end{tabular}

\subsection{Mechanical Properties of Alloy}

The effects of aging temperature and stress on the mechanical properties of alloy were studied by using an orthogonal test. The experimental method and results are summarized in Table 3. The results suggest that aging temperature has an obvious influence on the mechanical properties of the alloy. Tensile strength and yield strength first increases, and then decreases while the aging temperature is rising.

Table 3. Mechanical properties of the alloy after creep aging.

\begin{tabular}{ccccc}
\hline Temperature $/{ }^{\circ} \mathbf{C}$ & Stress/MPa & Tensile Strength/MPa & Yield Strength/MPa & Elongation/\% \\
\hline 160 & 0 & $482.6 \pm 2.5$ & $331.6 \pm 3.4$ & $19.9 \pm 0.3$ \\
160 & 180 & $497.5 \pm 4.1$ & $362.4 \pm 5.6$ & $21.6 \pm 0.5$ \\
160 & 210 & $496.6 \pm 3.0$ & $358.6 \pm 3.6$ & $21.6 \pm 0.4$ \\
180 & 0 & $495.6 \pm 2.7$ & $443.4 \pm 3.4$ & $10.1 \pm 0.4$ \\
180 & 180 & $504.2 \pm 4.5$ & $463.2 \pm 4.8$ & $10.1 \pm 0.3$ \\
180 & 210 & $501.4 \pm 2.8$ & $461.1 \pm 3.1$ & $10.4 \pm 0.3$ \\
200 & 0 & $465.6 \pm 3.6$ & $372.6 \pm 4.2$ & $8.8 \pm 0.5$ \\
200 & 180 & $472.7 \pm 3.5$ & $417.3 \pm 4.6$ & $8.9 \pm 0.4$ \\
200 & 210 & $475.2 \pm 2.1$ & $419.9 \pm 2.6$ & $8.9 \pm 0.3$ \\
\hline
\end{tabular}




\subsection{Effect of Aging Temperature on Fatigue Fracture of Alloy}

Figure 4 shows the fatigue life of Al-Cu-Mg alloy under a constant maximum stress of $180 \mathrm{MPa}$ after $12 \mathrm{~h}$ of creep aging at different aging temperatures. It can be seen that the fatigue life of the alloy first increases, and then decreases with the increase of aging temperature under the same stress, and the highest is 90,971 cycles at $180{ }^{\circ} \mathrm{C}$. Meanwhile, the fatigue life of the alloy at $200{ }^{\circ} \mathrm{C}$ is lower than that at $160{ }^{\circ} \mathrm{C}$.

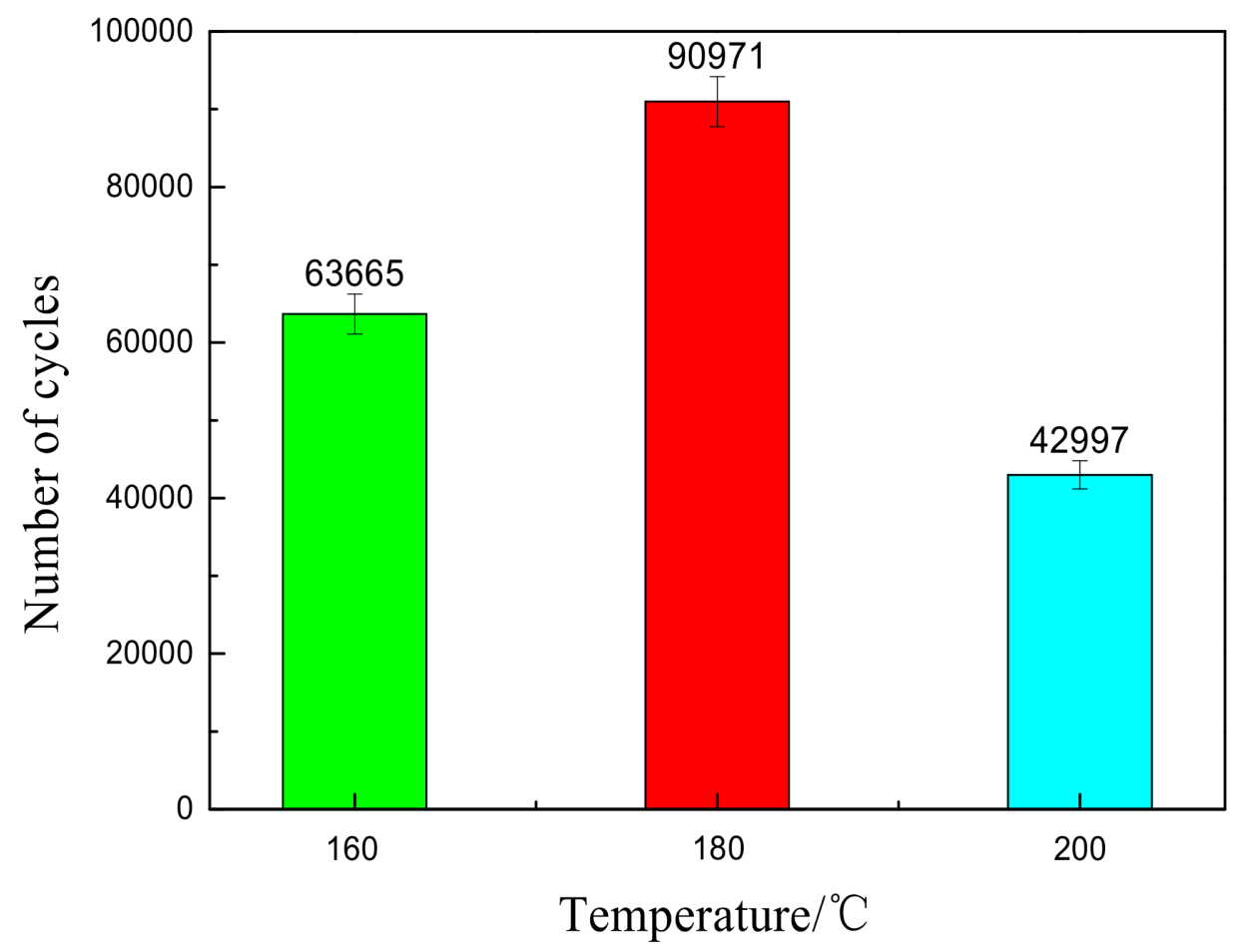

Figure 4. The fatigue life of the alloy under a constant stress of $180 \mathrm{MPa}$ after $12 \mathrm{~h}$ of creep aging at different aging temperatures.

Figures 5-7 show the fatigue fracture appearance of $\mathrm{Al}-\mathrm{Cu}-\mathrm{Mg}$ alloy under a constant stress of $180 \mathrm{MPa}$ after $12 \mathrm{~h}$ of aging at $160{ }^{\circ} \mathrm{C}, 180{ }^{\circ} \mathrm{C}$, and $200{ }^{\circ} \mathrm{C}$. These figures demonstrate that the fatigue surfaces can be divided into three regions: fracture nucleation, stable fatigue crack growth, and final fracture. In the fracture nucleation, the main cracks, some small secondary cracks, torn edges, and quasi-cleavage present a river pattern. The fracture has crystallographic characteristics, reflecting crack extensions along the different crystal planes and second-phase particles [20]. The fatigue life of metal materials mainly includes the fatigue cycles of fatigue crack and fatigue crack growth. Therefore, the larger the area of the fatigue source zone and stable fatigue crack growth, the greater the fatigue life. In addition, during the fatigue crack growth, a microtrace named fatigue striation appeared on the fatigue surface, which can be regarded as a fatigue cycle of the alloy. As a result, a narrower fatigue strip can also indicate that the fatigue life at $180{ }^{\circ} \mathrm{C}$ is higher. 

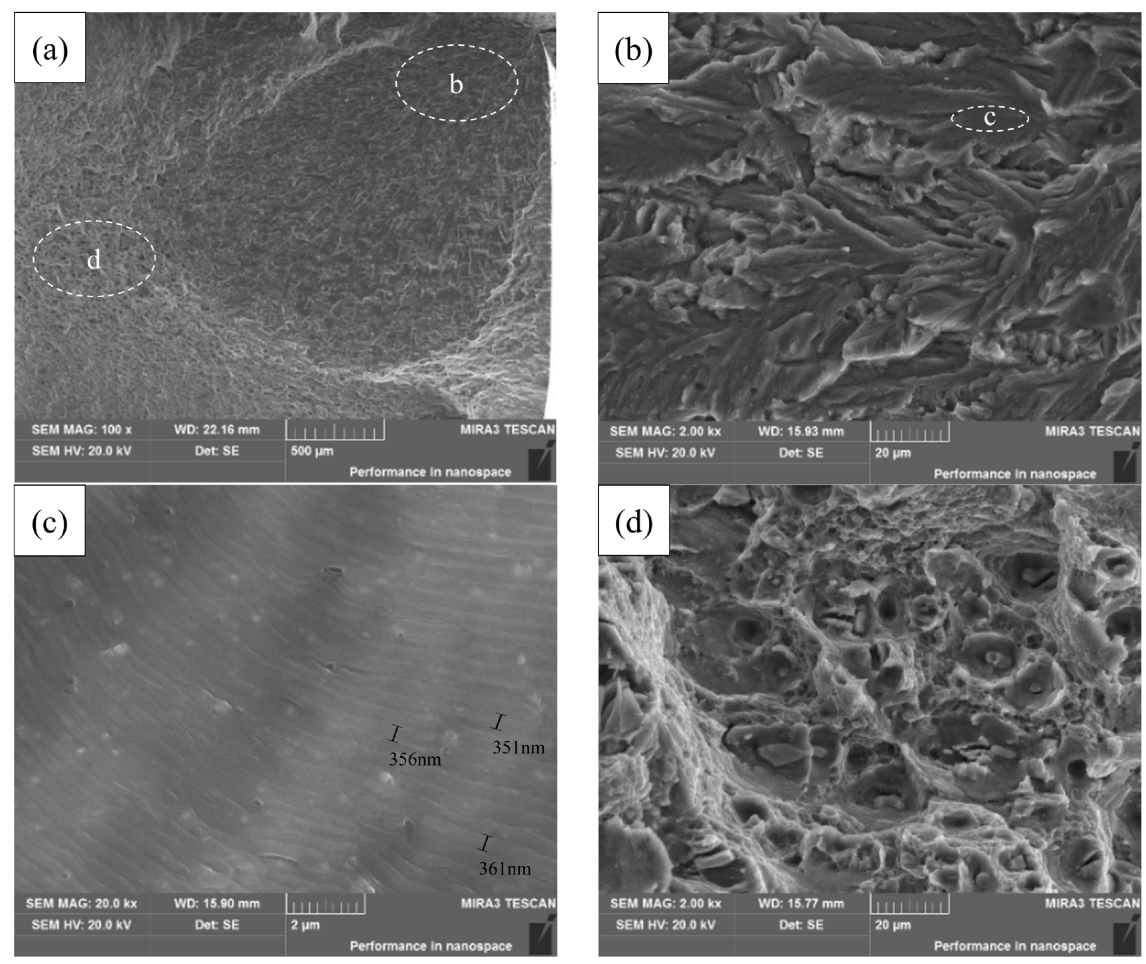

Figure 5. The fatigue fracture surfaces of $\mathrm{Al}-\mathrm{Cu}-\mathrm{Mg}$ alloy under $180 \mathrm{MPa}$ after $12 \mathrm{~h}$ of creep aging at $160^{\circ} \mathrm{C}$ : (a) full view; (b) fracture nucleation; (c) stable fatigue crack growth; (d) final fracture.
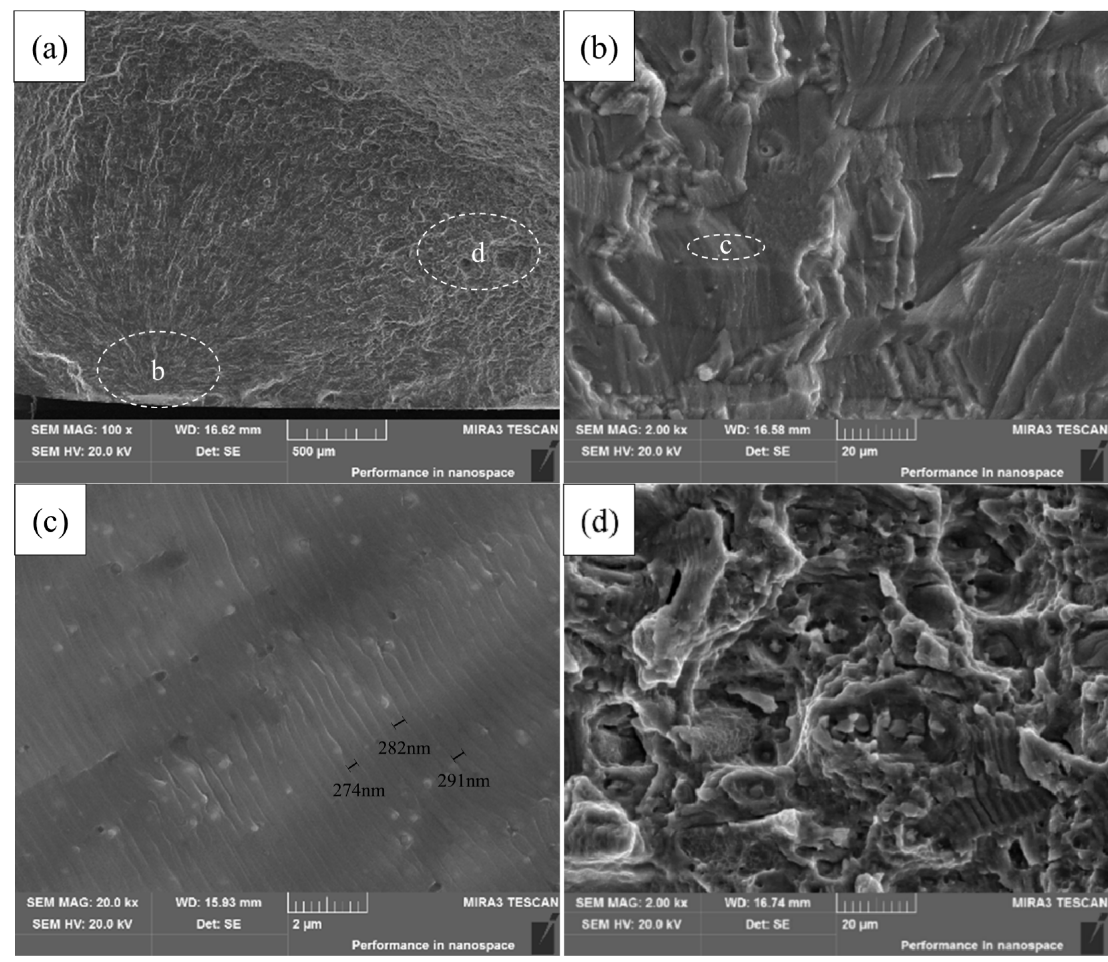

Figure 6. The fatigue fracture surfaces of $\mathrm{Al}-\mathrm{Cu}-\mathrm{Mg}$ alloy under $180 \mathrm{MPa}$ after $12 \mathrm{~h}$ creep aging at $180^{\circ} \mathrm{C}$ : (a) full view; (b) fracture nucleation; (c) stable fatigue crack growth; (d) final fracture [21]. 

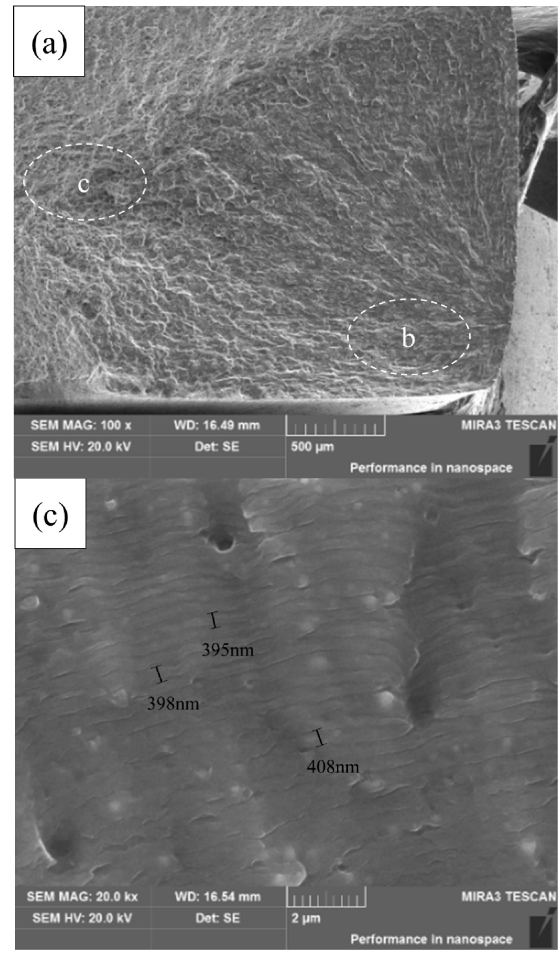

\section{(b)}

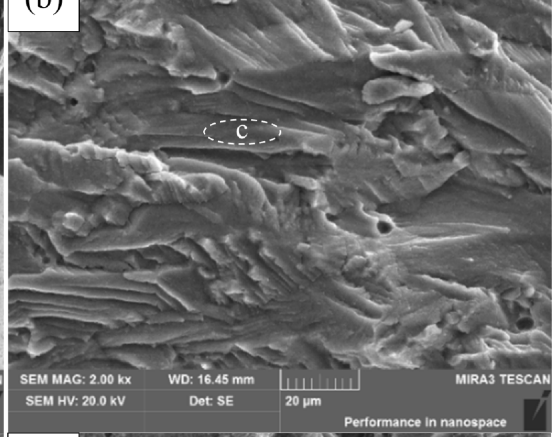

(d)

Figure 7. The fatigue fracture surfaces of Al-Cu-Mg alloy under $180 \mathrm{MPa}$ after $12 \mathrm{~h}$ of creep aging at $200^{\circ} \mathrm{C}$ : (a) full view; (b) fracture nucleation; (c) stable fatigue crack growth; (d) final fracture.

From Figure 5, it can be seen that the area of fatigue crack and fatigue crack growth is large under a constant stress of $180 \mathrm{MPa}$ after $12 \mathrm{~h}$ of creep aging at $160{ }^{\circ} \mathrm{C}$. Figure 6 shows the largest area of fatigue crack and fatigue crack growth at $180^{\circ} \mathrm{C}$, and its fatigue striation is more compact and regular than other conditions. While the creep aging temperature rises to $200^{\circ} \mathrm{C}$, in Figure 7 , the fatigue crack and fatigue crack growth zone of the alloy is the smallest. Its fatigue striation is accompanied by some microcracks, and is not as clear and compact as other conditions. In conclusion, with the increase of the creep aging temperature, the area of fatigue crack and fatigue crack growth first increases, and then decreases under the same stress. The distance between the fatigue striation changes according to the same rule. These indicate that the fatigue life first increases and then decreases with the increase of temperature, which is consistent with the data obtained from previous fatigue life tests.

\subsection{Effect of Stress on Fatigue Fracture of Alloy}

Figure 8 shows the fatigue life of Al-Cu-Mg alloy under different stress after $12 \mathrm{~h}$ of creep aging at $180{ }^{\circ} \mathrm{C}$. The fatigue life of alloy is only 37,510 cycles after $12 \mathrm{~h}$ of aging without stress, while it is obviously improved after stress is applied. However, the fatigue life decreases as the stress further increases. 


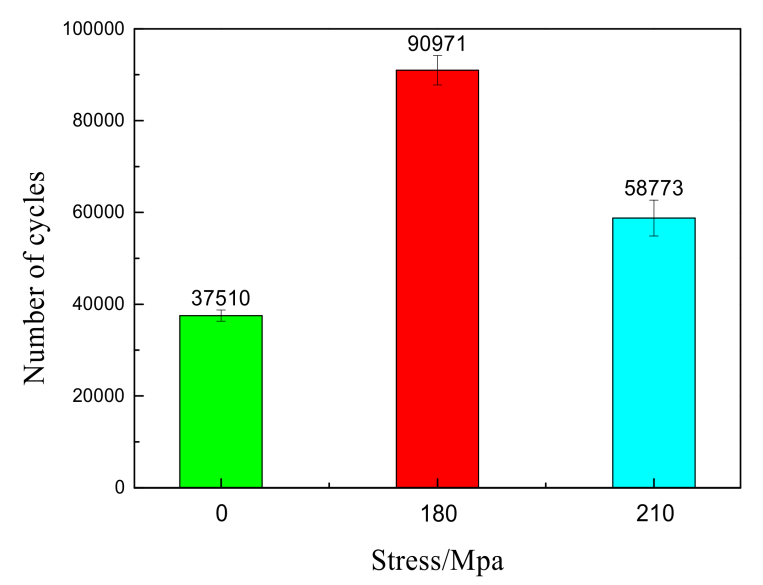

Figure 8. The fatigue life of the alloy under different stress levels after $12 \mathrm{~h}$ of creep aging at $180{ }^{\circ} \mathrm{C}$.

Figures 9 and 10 show the fatigue fracture appearance of $\mathrm{Al}-\mathrm{Cu}-\mathrm{Mg}$ alloy under different stress levels $(0 \mathrm{MPa}, 210 \mathrm{MPa})$ after $12 \mathrm{~h}$ of aging at $180^{\circ} \mathrm{C}$. It can be seen in Figure 9 that the area of fatigue crack and fatigue crack growth is small, but the area of final fracture is large. Moreover, there are some slender microcracks at the fatigue striation on the surface, which is quite different from that observed previously. These cracks can significantly accelerate the fatigue process and reduce the fatigue life. When the stress rises to $210 \mathrm{MPa}$, the area of fatigue crack and fatigue crack growth is larger than that of $0 \mathrm{MPa}$, as presented in Figure 10. Furthermore, the fatigue striation is also narrower, and there is no microcrack. Compared with $0 \mathrm{MPa}$ or $210 \mathrm{MPa}$, the fatigue striation of $180 \mathrm{MPa}$ is the narrowest, as revealed in Figure 6.

In summary, stress can significantly improve the fatigue life of alloy during aging. However, with the stress further increasing, the fatigue life of alloy is reduced on the grounds of the data obtained from previous fatigue life tests.
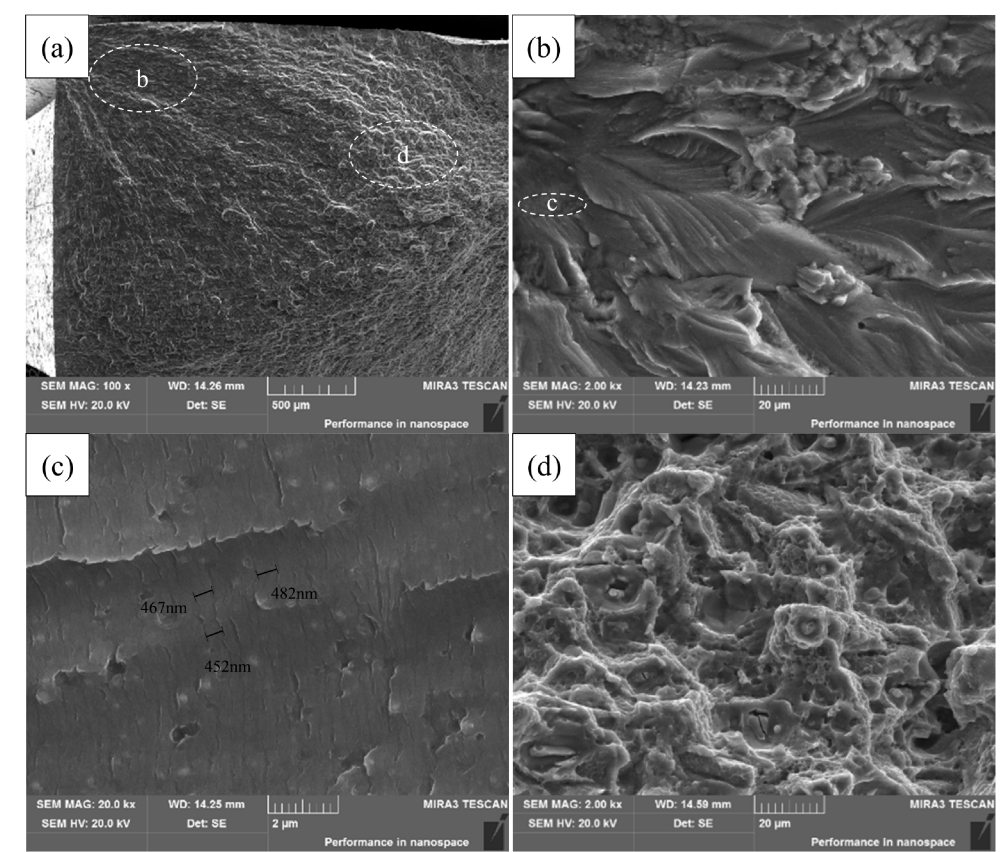

Figure 9. The fatigue fracture surfaces of $\mathrm{Al}-\mathrm{Cu}-\mathrm{Mg}$ alloy under $0 \mathrm{MPa}$ after $12 \mathrm{~h}$ of creep aging at $180^{\circ} \mathrm{C}$ : (a) full view; (b) fracture nucleation; (c) stable fatigue crack growth; (d) final fracture. 

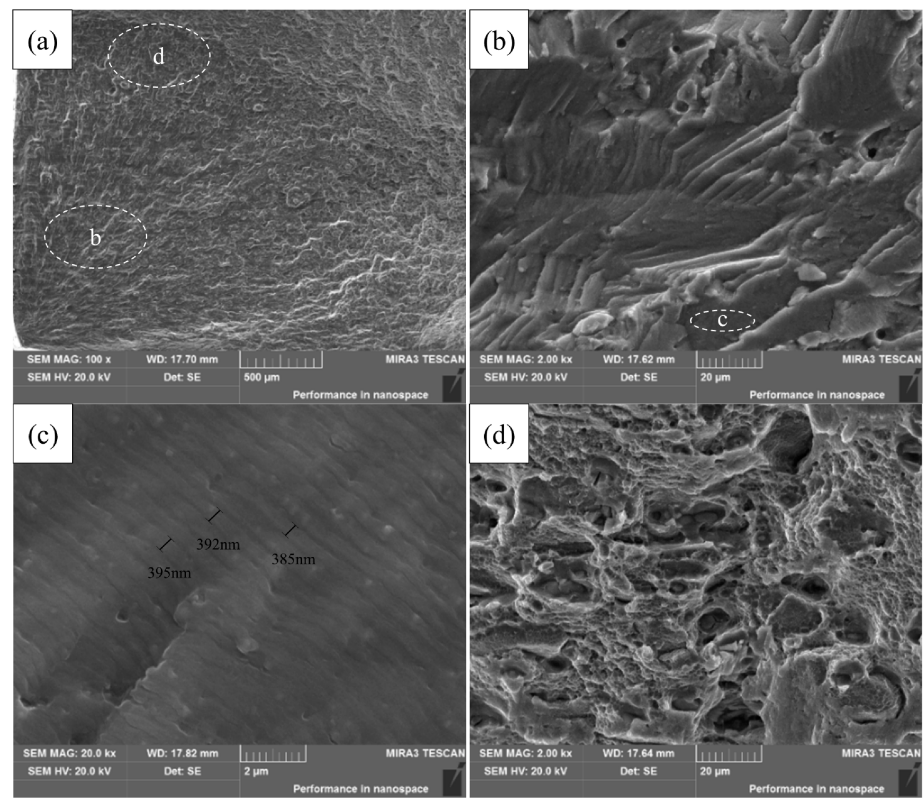

Figure 10. The fatigue fracture surfaces of A-Cu-Mg alloy under $210 \mathrm{MPa}$ after $12 \mathrm{~h}$ of creep aging at $180^{\circ} \mathrm{C}$ : (a) full view; (b) fracture nucleation; (c) stable fatigue crack growth; (d) final fracture.

\subsection{Relationship between Microstructure and Fatigue Fracture Behavior of Alloy}

\subsubsection{Effect of Aging Temperature}

Figure 11 shows the precipitation characteristics of Al-Cu-Mg alloy under $180 \mathrm{MPa}$ stress after $12 \mathrm{~h}$ of creep aging at $160{ }^{\circ} \mathrm{C}, 180{ }^{\circ} \mathrm{C}$, and $200{ }^{\circ} \mathrm{C}$. At an aging temperature of $160{ }^{\circ} \mathrm{C}$, there are Guinier-Preston-Bagaryatsky (GPB) zones in the grain interior under $180 \mathrm{MPa}$ stress after $12 \mathrm{~h}$. There are also rod-like precipitation phases in the grain interior, according to the relevant report [22]; this is called the $\mathrm{T}$ phase $\left(\mathrm{Al}_{20} \mathrm{Cu}_{2} \mathrm{Mn}_{3}\right)$, which is stable and forms during homogenization treatment or hot rolling. Meanwhile, dislocations appear in the grain interior due to long-term creep aging. There is neither a precipitation-free zone (PFZ) nor precipitation phase segregation at grain boundaries. Then, with the creep aging temperature rising to $180^{\circ} \mathrm{C}$, there are a large number of acicular $S$ phases dispersed in the grain interior, strongly impeding the movement of dislocations, as presented in Figure 11c. At the same time, coarse precipitates are observed around the grain boundaries without PFZ. When the creep aging temperature rises to $200{ }^{\circ} \mathrm{C}$, the fine phase $\mathrm{S}$ transforms to coarse phase $\mathrm{S}$. Meanwhile, the phases grow up, and the grain boundary segregation occurs to form a continuous chain. The $105 \mathrm{~nm}$ wide PFZ forms at the grain boundaries, because the solute atoms preferentially precipitate at the grain boundaries.

During creep aging, more fine and dispersed precipitation phases are formed under the $180^{\circ} \mathrm{C}$ condition than the others. Moreover, the large volume fraction of precipitation phases make the dislocation movement become more difficult, so it has a higher strength and greater fatigue crack propagation resistance [23]. Furthermore, with the temperature rising, precipitation phases also appear at the grain boundary, and finally, PFZ forms. In conclusion, the increasing of temperature will promote the growth of precipitation phases and PFZ. 


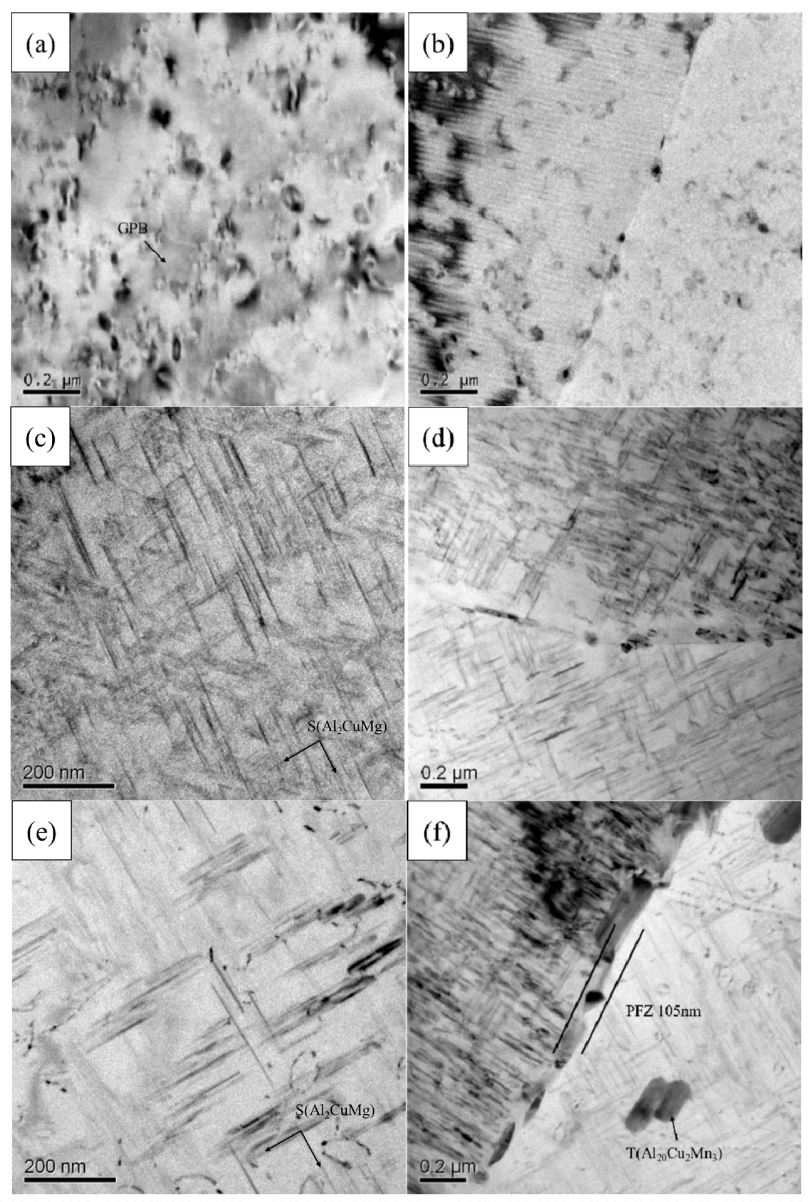

Figure 11. TEM micrographs of $\mathrm{Al}-\mathrm{Cu}-\mathrm{Mg}$ alloy under $180 \mathrm{MPa}$ after $12 \mathrm{~h}$ of creep aging at different temperature: $(\mathbf{a}, \mathbf{b}) 160^{\circ} \mathrm{C}$; (c,d) $180{ }^{\circ} \mathrm{C}$; (e,f) $200^{\circ} \mathrm{C}$.

\subsubsection{Effect of Stress}

Figure 12 shows the TEM of Al-Cu-Mg alloy under different stress levels after $12 \mathrm{~h}$ of creep aging at $180{ }^{\circ} \mathrm{C}$. There are small and dispersed acicular $\mathrm{S}$ phases in the grain interior, when stress is $0 \mathrm{MPa}$. The number of the precipitation phases is less compared with the $180 \mathrm{MPa}$ condition because of the addition of stress. Stress deforms the alloy and increases dislocations in the grain interior, which provides a favorable nucleation position for the heterogeneous nucleation of solute atoms, thus accelerating the precipitation phases, which then precipitate more quickly. Meanwhile, there are precipitation phases nucleating at grain boundaries and a PFZ about $125 \mathrm{~nm}$ wide appearing under the stress of $0 \mathrm{MPa}$. However, compared with the stress at $180 \mathrm{MPa}$, there is neither a PFZ nor a precipitation phase. This is because the existence of stress brings about a large number of dislocations in the grain interior during the aging process, promoting precipitation phases precipitating at these dislocations, and making phases precipitate with uniform driving force. When stress is $210 \mathrm{MPa}$, the size of the precipitation phases in the grain interior is larger than that at $180 \mathrm{MPa}$, due to the increasing stress, which advances the precipitation process.

At the same temperature, the fatigue life of the alloy under $0 \mathrm{MPa}$ is shorter than that after creep aging. This is because, on the one hand, stress can generate a part of plastic deformation, which increases dislocation density in the grain interior during the aging process, causing precipitation phases to precipitate more rapidly. On the other hand, the precipitating driving force in the grain interior and grain boundaries becomes more uniform due to the application of stress, so the PFZ narrows or disappears. These will reduce the stress concentration at grain boundaries, increasing the 
fatigue life of the alloy. However, overhigh stress brings about an improvement of the precipitation process and induces the appearance of a PFZ so that the fatigue life of the alloy declines.

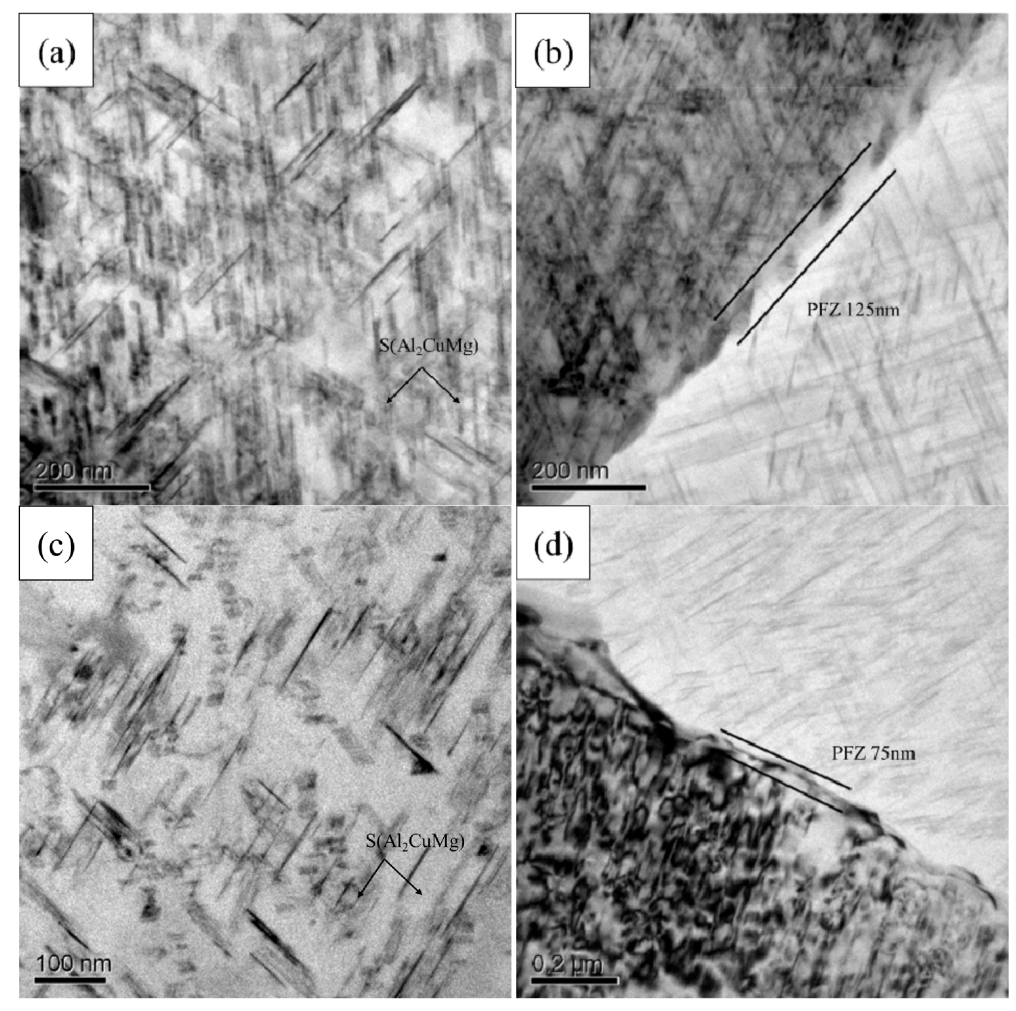

Figure 12. TEM micrographs of Al-Cu-Mg alloy under different stress levels after $12 \mathrm{~h}$ of creep aging at $180{ }^{\circ} \mathrm{C}:(\mathbf{a}, \mathbf{b}) 0 \mathrm{MPa} ;(\mathbf{c}, \mathbf{d}) 210 \mathrm{MPa}[21]$.

There are many factors that affect the fatigue behavior of $\mathrm{Al}-\mathrm{Cu}-\mathrm{Mg}$ alloy, such as fatigue conditions, surface state, dimensions, and materials. The main purpose of this study is to research the effect of creep aging parameters on the fatigue fracture of $\mathrm{Al}-\mathrm{Cu}-\mathrm{Mg}$ alloy. The creep aging parameters (aging temperature, stress level) can obviously change the aging precipitation characteristics and microstructure before they ultimately affect the fatigue fracture behavior. The precipitation sequence of Al-Cu-Mg alloy used in this paper has generally been believed: supersaturated solid solution (SSSS) $\rightarrow$ solute clusters $\rightarrow$ Guinier-Preston-Bagaryatsky (GPB) $\rightarrow$ S [24-26]. The effects of aging precipitation characteristics on the fatigue properties of the alloy is reflected in three aspects $[27,28]$ :

(1) During the creep aging process, the strengthening phases in the grain interior can precipitate under the combined impact of stress and temperature. These precipitation phases in the matrix impede the dislocations movement and improve the strength and anti-plastic deformation of alloy until they eventually reduce the deformation damage during the fatigue process and prolong fatigue life.

(2) The precipitation phases in the grain interior are semi-coherent or incoherent with the matrix, causing dislocations passing round the precipitation phases and leaving a dislocations loop. It makes dislocations unable to slip repeatedly in grains, which leads to the dislocations easily slipping to the grain boundary. The precipitation phase is not conducive to the crack growth and the reduction of deformation damage.

(3) The precipitation-free zone (PFZ) and coarse particles along the grain boundaries will reduce the strength of grain boundaries, so that the dislocations are more likely to slip at the grain boundary. These can increase the stress concentration of grain boundaries, forming cracks easily along the grain boundaries. 


\section{Conclusions}

In this paper, the creep behavior, mechanical properties, microstructure, and fatigue crack behavior of an Al-Cu-Mg alloy were studied.

(1) With the increase of temperature and stress, the creep strain of the alloy is improved. As the temperature rises, the tensile strength and yield strength first increase, and then decrease. The mechanical properties of alloy are improved after creep aging, but stress has a weak effect on the mechanical properties.

(2) The process parameters can obviously impact the fatigue life of the alloy. The fatigue life first increases, and then decreases with the rise of both temperature and stress. Both overhigh temperature and stress can shorten the fatigue life. The best fatigue life is 90971 cycles at $180{ }^{\circ} \mathrm{C}$ under $180 \mathrm{MPa}$ in this study.

(3) The precipitation characteristics of alloy are the main reason for the fatigue life change of the alloy. When the precipitation phases are fine and dispersed, the strength and anti-plastic deformation of the alloy are improved, and fatigue life increases. However, when the precipitation phases become coarse, the precipitation phases cannot be cut by dislocation, so the fatigue life dropped. Besides, the PFZ at the grain boundary is a weak part of alloy, where the fatigue life decreases with a wide PFZ.

Author Contributions: Lihua Zhan and Xintong Wu proposed the original project and supervised the investigation. Xintong $\mathrm{Wu}$, Youliang Yang and Guiming Liu performed testing and characterization. Xintong Wu and Xun Wang performed data analysis and wrote the paper. Yongqian Xu contributed consultation, data analysis.

Acknowledgments: The authors gratefully acknowledge Financial Support of the National Science Foundation of China (No. 51675538) and the National Basic Research Program of China (No. 2014CB046502), for funding the work reported.

Conflicts of Interest: The authors declare no conflict of interest.

\section{References}

1. Zhan, L.; Lin, J.; Dean, T.A. A review of the development of creep age forming: Experimentation, modelling and applications. Int. J. Mach. Tool Manuf. 2011, 51, 1-17. [CrossRef]

2. Xu, Y.; Zhan, L.; Li, W. Effect of pre-strain on creep aging behavior of 2524 aluminum alloy. J. Alloys Compd. 2017, 691, 564-571. [CrossRef]

3. Yang, Y.; Zhan, L.; Shen, R.; Yin, X.; Li, X.; Li, W.; Huang, M.; He, D. Effect of pre-deformation on creep age forming of 2219 aluminum alloy: Experimental and constitutive modelling. Mater. Sci. Eng. A 2017, 683, 227-235. [CrossRef]

4. Lei, C.; Yang, H.; Li, H.; Shi, N.; Zhan, L. Dependences of microstructures and properties on initial tempers of creep aged 7050 aluminum alloy. J. Mater. Process. Technol. 2017, 239, 125-132. [CrossRef]

5. Xu, Y.; Zhan, L.; Ma, Z.; Huang, M.; Wang, K.; Sun, Z. Effect of heating rate on creep aging behavior of Al-Cu-Mg alloy. Mater. Sci. Eng. A 2017, 688, 488-497. [CrossRef]

6. Ho, K.C.; Lin, J.; Dean, T.A. Modelling of springback in creep forming thick aluminum sheets. Int. J. Plast. 2004, 20, 733-751. [CrossRef]

7. Zhan, L.; Lin, J. , Dean, T.A.; Huang, M. Experimental studies and constitutive modelling of the hardening of aluminium alloy 7055 under creep age forming conditions. Int. J. Mech. Sci. 2011, 53, 595-605. [CrossRef]

8. Xu, F.; Zhang, J.; Deng, Y.; Zhang, X. Precipitation orientation effect of 2124 aluminum alloy in creep aging. Trans. Nonferrous Met. Soc. China 2014, 24, 2067-2071. [CrossRef]

9. Yang, Y.; Zhan, L.; Li, J. Constitutive modeling and springback simulation for 2524 aluminum alloy in creep age forming. Trans. Nonferrous Met. Soc. China 2015, 25, 3048-3055. [CrossRef]

10. Chen, Y.; Pan, S.; Zhou, M.; Yi, D.; Xu, D.; Xu, Y. Effects of inclusions, grain boundaries and grain orientations on the fatigue crack initiation and propagation behavior of 2524-T3 Al alloy. Mater. Sci. Eng. A 2013, 580, 150-158. [CrossRef]

11. Siddiqui, R.A.; Abdul-Wanhab, S.A.; Pervez, T. Effect of aging time and aging temperature on fatigue and fracture behavior of 6063 aluminum alloy under seawater influence. Mater. Des. 2008, 29, 70-79. [CrossRef] 
12. Liu, Y.; Liu, Z.; Li, Y.; Xia, Q.; Zhou, J. Enhanced fatigue crack propagation resistance of an Al-Cu-Mg alloy by artificial aging. Mater. Sci. Eng. A 2008, 527, 4070-4075.

13. Chen, X.; Liu, Z.; Lin, M.; Ning, A.; Zeng, S. Enhanced Fatigue Crack Propagation Resistance in an Al-Zn-Mg-Cu Alloy by Retrogression and Reaging Treatment. J. Mater. Eng. Perform. 2012, 21, $2345-2353$. [CrossRef]

14. Zhou, Z.; Zhang, J.; Deng, Y. Creep forming heat treatment technology of Al-Cu-Mg alloy. Chin. J. Nonferrous Met. 2016, 26, 1607-1614. (In Chinese)

15. Chen, Y.; Deng, Y.; Wan, L.; Jin, K.; Xiao, Z. Microstructures and Properties of 7050 Aluminum Alloy Sheet During Creep Aging. J. Mater. Eng. 2012, 2, 71-76. (In Chinese)

16. Quan, L.; Zhao, G.; Gao, S.; Muddle, B.C. Effect of pre-stretching on microstructure of aged 2524 aluminium alloy. Trans. Nonferrous Met. Soc. China 2011, 21, 1957-1962. [CrossRef]

17. Marceau, R.; Sha, G.; Ferragut, R.; Dupasquier, A.; Ringer, S. Solute clustering in Al-Cu-Mg alloys during the early stages of elevated temperature ageing. Acta Mater. 2010, 58, 4923-4939. [CrossRef]

18. Starke, E.A.; Sraley, J.T. Application of modern aluminum alloys to aircraft. Prog. Aerosp. Sci. 1996, 32, 131-172. [CrossRef]

19. Huda, Z.; Zaharinie, T.; Min, G. Temperature effects on material behavior of aerospace aluminum alloys for subsonic and supersonic aircraft. J. Aerosp. Eng. 2010, 23, 124-128. [CrossRef]

20. Zheng, Z.; Cai, B.; Zhai, T.; Li, S. The behavior of fatigue crack initiation and propagation in AA2524-T34 alloy. Mater. Sci. Eng. A 2011, 528, 2017-2022. [CrossRef]

21. Li, W.; Zhan, L.; Liu, L.; Xu, Y. The effect of creep aging on the fatigue fracture behavior of 2524 aluminum alloy. Metals 2016, 6, 215. [CrossRef]

22. Xu, Y.; Zhan, L.; Xu, L.; Huang, M. Experimental research on creep aging behavior of Al-Cu-Mg alloy with tensile and compressive stresses. Mater. Sci. Eng. A 2017, 682, 54-62. [CrossRef]

23. Bray, G.H.; Glazov, M.; Rioj, R.J.; Lib, D.; Gangloffb, R.P. Effect of artificial aging on the fatigue crack propagation resistance of 2000 series aluminum alloys. Int. J. Fatigue 2001, 23, 265-276. [CrossRef]

24. Liu, Z.; Chen, J.; Wang, S.; Yuan, D.; Yin, M.; Wu, C. The structure and the properties of S-phase in AlCuMg alloys. Acta Mater. 2011, 59, 7396-7405. [CrossRef]

25. Ratchev, P.; Verlinden, B.; Smet, P.; Houtte, P. Precipitation hardening of an Al- $4.2 \mathrm{wt} \% \mathrm{Mg}-0.6 \mathrm{wt} \% \mathrm{Cu}$ alloy. Acta Mater. 1998, 46, 3523-3533. [CrossRef]

26. Sha, G.; Marceau, R.K.W.; Gao, X.; Muddle, B.C.; Ringer, S.P. Nanostructure of aluminium alloy 2024: Segregation, clustering and precipitation processes. Acta Mater. 2011, 59, 1659-1670. [CrossRef]

27. Kamp, N.; Gao, N.; Starink, M.J.; Sinclair, I. Influence of grain structure and slip planarity on fatigue crack growth in low alloying artificially aged 2xxx aluminium alloys. Int. J. Fatigue 2007, 29, 869-878. [CrossRef]

28. Liu, M.; Liu, Z.; Bai, S.; Xia, P.; Ying, P.; Zeng, S. Solute cluster size effect on the fatigue crack propagation resistance of an underaged Al-Cu-Mg alloy. Int. J. Fatigue 2016, 84, 104-112. [CrossRef] 